\title{
Attributes of Biothic Indicators as an Instrument for Assessing Ecosystem Integrity
}

\author{
Paula Catalina Pinilla-Cortés, Jaime Alberto Moreno-Gutiérrez \\ Faculty of Environment and Natural Resources, District University Francisco José de Caldas, Bogotá, Colombia \\ Email: pcpinillac@correo.udistrital.edu.co, jamemoreno@gmail.com
}

How to cite this paper: Pinilla-Cortés, P.C. and Moreno-Gutiérrez, J.A. (2019) Attributes of Biothic Indicators as an Instrument for Assessing Ecosystem Integrity. Open Access Library Journal, 6: e5540. https://doi.org/10.4236/oalib.1105540

Received: June 13, 2019

Accepted: July 2, 2019

Published: July 5, 2019

Copyright $\odot 2019$ by author(s) and Open Access Library Inc.

This work is licensed under the Creative Commons Attribution International License (CC BY 4.0).

http://creativecommons.org/licenses/by/4.0/

\begin{abstract}
The biotic indicators, or bioindicators, constitute a reference that contributes to the resolution of different issues associated with the state and evolution of the natural habitats where they are located. The information they provide can be interpreted mainly in terms of sensitivity, tolerance to different types of stress and the integrity of a forest ecosystem. The objective is (commentary 1) to present the characteristics of the bioindicators, which are capable of reflecting the ecosystemic integrity and provide valuation references in forest habitats. The attributes were reported thanks to the methodological strategy of bibliographic review through a theoretical sampling, taking into account 44 bibliographical sources that covered a time lapse between 1985 and 2016. As a result of the review, there were obtained a total of seventeen prevalent attributes in bioindicator species. Part of the discussions focus on recognizing that the study of bioindicators, and in general the principles associated with bioindication, provide potential criteria to resolve concerns beyond fully biological or ecological aspects and that are relevant in scenarios of environmental economic and/or ecological valuation. Finally, this review concludes that it has been possible to present a consensus of attributes and, at the same time, show some emerging attributes associated with biotic indicators that contribute to the analysis of the selection of bioindicator species in different studies.
\end{abstract}

\section{Subject Areas}

Human Resource Management

\section{Keywords}

Economic Valuation, Ecosystem Integrity, Forested Habitat, Human Well-Being 


\section{Introduction}

According to the objectives of sustainable development, the components and interrelations that are part of natural resources contribute to the permanence of the integrity of ecosystems and this will be reflected in the quality of life of the human population [1]. The ecosystemic integrity is linked with the maintenance of a natural environment by itself and in the contribution of benefits that the habitat provides to the human being. In this way, the economic valuation of the biological resources and their diversity is related to the benefits that these resources contribute to society [1]. These benefits are concretized through ecosystem services, therefore, and taking into account with the contribution of this article, it is important to establish a characterization associated with the attributes that represent the biotic indicators and how they can generate value criteria, because both the Economic System and the human well-being depend on maintaining the integrity of ecosystems and natural environments such as forests [2].

The dynamics that characterize this type of habitat have a determining influence on the quality of life of human beings for both present and future generations. In the mid-twentieth century, authors such as Landers, Verner and Thomas [3] and Riiters, Law, Kucera, Gallant, Dc Velice and Palmer [4] recognize difficulties in using bioindicators to assess population trends at the species level, to study general aspects of natural life and to assess habitat quality. These authors indicate that the criteria used to select indicators are ambiguous, therefore they recommend using biondicators as part of a comprehensive analysis strategy or situations centered on key habitats areas. This strategy may include indicators to monitor the structural and functional composition at multiple levels of organization in a natural environment [5].

The use of species as indicators in monitoring environmental conditions has been established as a tradition in ecology, environmental toxicology, pollution control, forestry, wildlife and management of distribution areas. These are some of the fields of action of the bioindicators, however, when developing a research that takes into account these issues, there have been conceptual and procedural differences [6] [7].

This article aims to present attributes or characteristics that are part of the bioindicator species and how these characteristics are able to reflect ecosystem integrity and at the same time, to provide a significant point of reference for valuation in forest habitats. Methodologically, the article is based on academic and research studies which have shown some attributes that characterize biotic indicators. As a product of the review, an accumulation curve (Software Estimates 9.1.0) is proposed with the intention of complement the characterization made and represents the consensus attributes obtained through theoretical sampling. Also, it is presented a list and description of attributes that, despite not having a relevant representativeness within the sampling, are considered to contribute to the identity of a bioindicator and the way in which it is unders- 
tood.

It is necessary to contribute to the recognition of key monitoring attributes to identify biological characteristics, ecological processes and biophysical interactions that take place in natural environments, the recognition of these attributes has to do with the synthesis of the information available on the subject, therefore it is assumed the importance of proposing theoretical samples that for the case of this article have to do with bioindicator species as a study model. The visualization of attributes of these species can contribute to the resolution of a problem related to the management of natural environments, given that the consensus and the way in which the bioindicator species can be understood in the natural environment constitute in themselves management units and points reference of analysis.

Given the above, it is expected that the elements contributed help resolve not only ambiguities in bioindication but also provide insights into the management of natural environments in terms of ecosystem valuation and the evaluation of their integrity considering that in many cases, information is limited and operates under degrees of uncertainty because there is no base line of generic attributes that reflect generalities according to the logic and complexity under which ecosystems operate.

Initially, the structure of the document presents issues related to the logic of biotic indicators, principles associated with ecosystem integrity, ecosystem assessment and human preferences. Results are presented as a part of a theoretical sampling, which describe characteristics of a biotic indicator according to a consensus of attributes, later and according to the typology of the attributes, it is possible to propose analysis questions about the management of the environments which have to do with the intervention of human beings according to their preferences; finally, a brief conclusion exposes general elements provided by the article and some limitations from the information generated (See Figure $1)$.

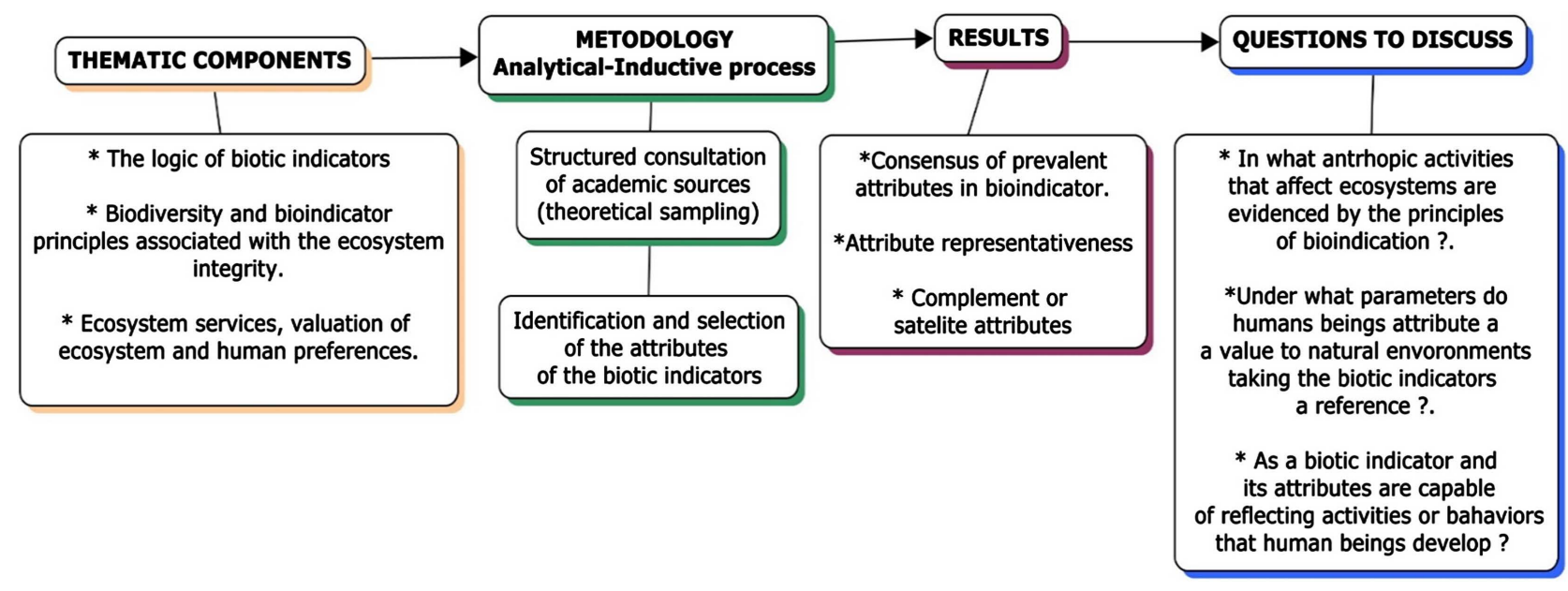

Figure 1. Summary graph of the document. 


\section{Development of the Topic: The Logic of Biotic Indicators}

Biotic indicators or bioindicators are known as species of plants and animals that show changes in presence-absence, condition and/or behavior on the health and state of a given ecosystem due to certain stresses that are generated in the natural environment. These tensions show quantitative and qualitative changes both in the structure and in the natural functioning of biotic communities [8]. In contrast, Büch [7] describes that biotic indicators can be defined as communities, populations or organisms that in ideal cases represent a biocoenosis and can provide information about the state or differentiated behavioral changes assumed by an ecosystem. This information can be used as a reference point for valuation because, according to economic principles and anthropocentric postures, ecosystem integrity beyond being a strictly ecological issue, incorporates measures that reflect the ability of the ecosystem to respond to the demands of the population human [9].

An indicator species can be defined as an organism whose characteristics are used as an attribute index. It is useful when is expensive to evaluate the conditions of a landscape in its entirety [3]. These species can be considered as shortcuts or instruments to approach the complexity of natural environments. In general, every organism is an indicator of the conditions of the environment in which it develops. This due to its existence in a given time and space responds to its ability to adapt to different environmental factors and both its presence and its abundance provide a signal on some process or state in the system in which it lives [10]. A particular event that generates a disturbance will also cause a series of changes in organisms whose magnitude will depend on the duration of the impact, its intensity and nature. The action can be direct or indirect and, usually, when a disturbance extends over time, it goes from individual or organismic responses (biochemical and physiological) to population, community and ecosystem responses [3] [10].

A biological indicator tolerates effects caused by an agent that generates a disturbance and, as a consequence, it shows some kind of compensatory or tolerant response. These responses indicate that the species can maintain a normal functioning, which requires a metabolic expense, or it can also be that a biological indicator does not only describe disturbing conditions but can also provide information associated with pristine and quality conditions of a given habitat [10]. The importance of using biological indicators is related to the fact that these species detect processes and factors in ecosystems, which has advantages, such as:

- The species and the biotic communities respond to cumulative effects that, at a certain moment, a sampling of chemical or physical variables is ignored [8] [10].

- The bioindicators allow to detect the appearance of polluting elements.

- As it is not feasible to take samples of the entire biota, the selection of some indicator species reduces and simplifies costs in the evaluation of the state of the ecosystems [11] [12]. 
According to Pinilla [10], the measurable parameters in a biological indicator depend on the taxonomic range that is being studied. The author proposes four levels:

1) Biochemical level (concentration of hormones and steroids, membranes, RNA/DNA changes)

2) Physiological level (growth of organisms, oxygen exchange rate-assimilation, oxygen consumption, nitrogen balance)

3) Population level (growth, birth and death rates, survival, relative abundance, density)

4) Community level (diversity, similarity, composition, coverage, productivity, biomass).

Noss [6] describes that there is no species that fully complies with all the characteristics referred to the ideal attributes of a biotic indicator. So, the author recommends using groups of species that can be complemented according to a doubt that is pretended to be solved. Similarly, according to Landers, Verner and Thomas [3], given the high complexity of natural systems, it is improbable that a single species could serve as an index of the structure and function of the community or ecosystem.

Typically, many of the studies that consider bioindicator species expect to obtain predictable physiological responses to an alteration that can be evidenced through the species that are taken as a reference for monitoring in a natural scenario. The alterations are translated as an affectation to the ecosystems and, usually, occur by activities of productive or industrial order, such as the pollution, presence of heavy metals, agrochemicals, pesticides and other toxic agents whose impacts tend to have effects on the species associated with the natural environment [7].

According to this reality, questions appear about the way in which biotic indicators are used and how the concept of bioindication itself is understood. Given that, although it is true that these species can be a reference that provides information on the presence of diverse impacts from the design of standardized conditions in a laboratory with partially predictable events, this causes that the application of bioindicators in many research studies is devoted in a hegemonic way to this purpose, ignoring other references and, even, other discussions that refer alternative questions that do not necessarily have to be controlled or expected.

\section{Biodiversity and Bioindication: Principles Associated with Ecosystem Integrity}

The ecosystem processes are complex and the number of species that can be taken as a unit of study to approach the understanding of that complexity is also broad, so it is not easy to assess the integrity of an ecosystem directly. Taking into account that the integrity of natural environments is the result of the network of ecological interactions, it is often useful to use bioindicators to evaluate aspects concerning integrity [11]. A bioindicator offers a tool to evaluate these 
processes concerning to natural environments, which are highly stochastic, understanding by stochasticity the condition that represents the nature of the multiplicity of dynamics and energy flows in the ecosystems and that contributes to the maintenance of the biodiversity and the quality of the habitat that supports that biodiversity [11].

Ecosystem integrity is a factor associated with the resilience of natural environments and their ability to absorb and assimilate disturbances in fundamental processes of change. It also intervenes in the conservation of biodiversity and the natural processes that nest the ecosystem and that, at the same time, are linked to the sustainable provision of a range of natural assets and services that provide a particular natural environment [2]. It is clear that the conservation of integrity, the permanence of the structure and the function of processes inherent to ecosystems occur within a natural range of variation [11]. Therefore, it is not species diversity per se that is important for integrity, but rather the way in which that diversity is organized in a system of harmony and coherence. This organization, together with resilience and productivity, determine the health of the ecosystem and, consequently, its integrity.

Species diversity seems to play two fundamental roles in the self-organization of ecosystems: first, it provides links in which energy flows by giving the system functional properties and, second, the species diversity increases the productivity of ecosystems by employing a greater number of possible paths for energy flow and nutrient cycling. In the same way, diversity contributes to the resilience of the ecosystem in order for it to respond to unexpected impacts. Costanza, Cumberland, Daly, Goodland and Nogaard [13], affirm that the species keep the system resilient and absorb disturbances, are important in phases of liberation and reorganization, therefore, biodiversity could be interpreted as a necessary containerfor the evolution of all forms of life.

The bioindicator species are a reference on the ecological processes of which they are a part, also on the health of the biota or the ecological integrity of the landscape [12]. If a biologically significant pattern was reported in the indicator species or group, it would be a signal that it could be interpreted in terms of change with respect to biota and, therefore, with respect to the ecological integrity of the landscape [13]. Therefore, the focal selection of species is useful in studies related to risk or vulnerability at the level of species or biological communities, recognizing that organisms or groups of organisms exert natural control in the ecosystem, contribute and maintain sources of information and contribute to the resilience of the system [13].

Large-scale studies involve knowledge of the cause and a scope around what is intended to be evaluated. The evaluation cannot be carried out according to species or particular groups of species taking into consideration each population of plant, animal or microbe in the landscape and neither with each of the interactions and processes related to integrity. As mentioned, these factors cannot be controlled and are presented stochastically in response to the dynamics of a natural environment, so it is prudent to select species or a particular group of spe- 
cies that can be complemented to support a problem of decision, even to integrate study categories related to processes or patterns beyond fully ecological systems to integrate other referents [11] [12].

\section{Ecosystem Services, Valuation of Ecosystems and Human Preferences}

Ecological systems sustain life on earth, without them the exercise of economic activity would not be possible. This, taking into account that ecosystems produce renewable resources and ecosystem services, which are understood as functions of the ecosystem that support and protect human beings activities or that have a transcendental influence on human well-being. Biodiversity itself at all levels contributes to the maintenance of the functions and services it provides. Despite this, it is well known that ecosystem services are rarely reflected in the prices of resources and are not considered by the modern industrial societies [1].

In 1999 Costanza and collaborators [13], propose that "in the long term, a healthy economy can exist symbiotically with a healthy ecology, both are so interdependent that isolating them for purely academic purposes has generated distortions and weak administrations". However, many current societies trust in future technological repairs and assume that it is possible to find substitutes for the loss of assets and services provided by natural environments, and people use narrow indicators of well-being and appropriate a vision that distances human populations from pristine ecosystems by putting substitutes that distort the essence of nature itself and that tend to economic growth.

Biodiversity and the connectivity relationships that are interweave in it provide benefits for the human population. These utilities are understood as ecosystem services that have a value of existence by pure moral conviction, however it is recognized that there are difficulties when quantifying judgments or moral decisions, which makes it easier to organize priorities through hierarchies.

When talking about sustainability, the preferences that involve a valuation cannot be considered as given or immovable. Therefore, the economy must assume a different and broad role, which implies to assume the uncertainty and indeterminacy where the valuation of the probabilities is unknown [14]. As mentioned before, the traditional paradigm from neoclassical economics assumes that preferences are immovable and static, and that the economic problem is to optimally satisfy these preferences. However, it is necessary to take into account that preferences change over time under the influence of education, advertising, cultural assumptions and other factors [13].

In the case of the valuation of ecological systems, the choices make explicit the complexity of the problem in a set of dimensions in which a discursive language emerges and this can take different paths, which makes diffuse and less explicit the issue of assessment and choice. The decisions that the society makes about ecosystems involve valuations, which can be explicit or not and can be undertaken using or not the knowledge proper of science and ecology. Whenever we 
have to take decisions, we are making assessments and it refers or identify the relative weights that we give to the various aspects of the problem [2] [13].

\section{Results: Attributes and Desirable Characteristics in a Biothical Indicator}

A biotic indicator is a species taken as a reference of information on synergistic or additive relationships related to ecosystems [8]. Under ideal conditions they present a wide speed of response to changes in the environment, given the capacity they have to respond to tensions which are exposed [15]. The response levels that these species can reflect reveal an early warning about the contamination or degradation of an ecosystem or they can also alert decision makers to stop or mitigate an observed impact [16].

Unlike the physical parameters that are useful during a generally short-term impact, the responses of a bioindicator are cumulative and observable after the causal event, so the effects are evident and lasting in the biota. In the same way, some impacts may not be detected through physical or chemical measurements, while cumulative effects at a biological level can be detected due to the responses can be observed and/or differentiated [8] [15] [17].

Caro and Doherty [18] and Gerhardt [19] describe that the species considered bioindicators must be abundant in all parts of the studied area, quantifiable and easy to collect. Likewise, they must generate a response in relation to a stressor and show a precise reaction to identify an impact at the ecosystem level. Also, they must have a stable taxonomy, principles supported by González and vallarino [17], Ferris, and Humphrey [20], Gayubo, González, Asis and Tormos [21]. The bioindicator species should not be subject to commercial exploitation because this situation hinders the appreciation of any trend in monitoring their abundance. Noss [6], describes that bioindicators must have a known taxonomic characterization, must be easy to sample and identify, and must represent relationships with other biological groups of interest.

The selection of appropriate bioindicators depends on a particular monitoring program or evaluation given that its nature can vary according to the state of the ecosystem and its socioeconomic and political conditions [8]. Although an ideal strategy may be to combine different biological groups or communities that present levels of differentiable sensitivity to evaluate the behavior of the biota [22], it is necessary to be clear that a single bioindicator species by itself does not fully satisfy all the mentioned requirements and that the difficulties on the use of bioindicators are directly associated with the natural fluctuations of complex systems that prevent approaching the problem in a quantitative or descriptive way [8]. Feinsinger [12] affirms that few groups of species, and to a lesser extent individual species, can satisfy all the criteria. However, some bioindicators are better than others, which is an essential evaluation requirement for the fulfillment of the objectives of a particular study.

A bioindicator species can be selected by a researcher according to reasons 
that tend to resolve issues related to the natural dynamics of an ecosystem. It can also respond to reasons of public interest or conservation, however in terms of economic valuation, it is necessary to take into account generalities that contribute to define and recognize the identity that is part of these species. In this point, two questions stand out: What is the raw material of the bioindication? What criteria allow a species to be taken as a bioindicator?

In order to start answering the previous questions, and returning to the importance associated to the report of generalities that describe the bioindicator species in terms of valuation, it is proposed a curve of accumulation of attributes reported in academic sources product of the theoretical sampling. From this, a consensus of 17 attributes is revealed, taking as a sampling unit the number of attributes obtained and assuming as a sampling effort the number of bibliographic sources consulted, which for this case corresponds to 44 sources (See Figure 2).

The oldest sources that are part of the consultation are assumed as primary sources or pioneering references. They contribute in different aspects to the discussions and debates on the topic, because this authors have generated problematizing scenarios around the proposed subject. More recent sources have considered some principles that have been described in the previous sources e.g. (Landers et al., 1988; Liverman et al., 1988; Noss, 1990; Cairns et al., 1993), and, regarding this, there are recognized some generalities related to the identification of qualities or attributes that bioindicator species can show.

The 17 attributes reported in the sampling can be classified into three categories: 1) attributes of a biological-ecological order, 2) attributes of a technical nature and 3) attributes that reflect a social or economic relevance. Consequently, a brief description by attribute is presented. This order of the description was made taking into account the representativeness and temporality of the sampling depending on the total of consulted sources, and the range of time in which they have been referred by the scientific literature (See Table 1).

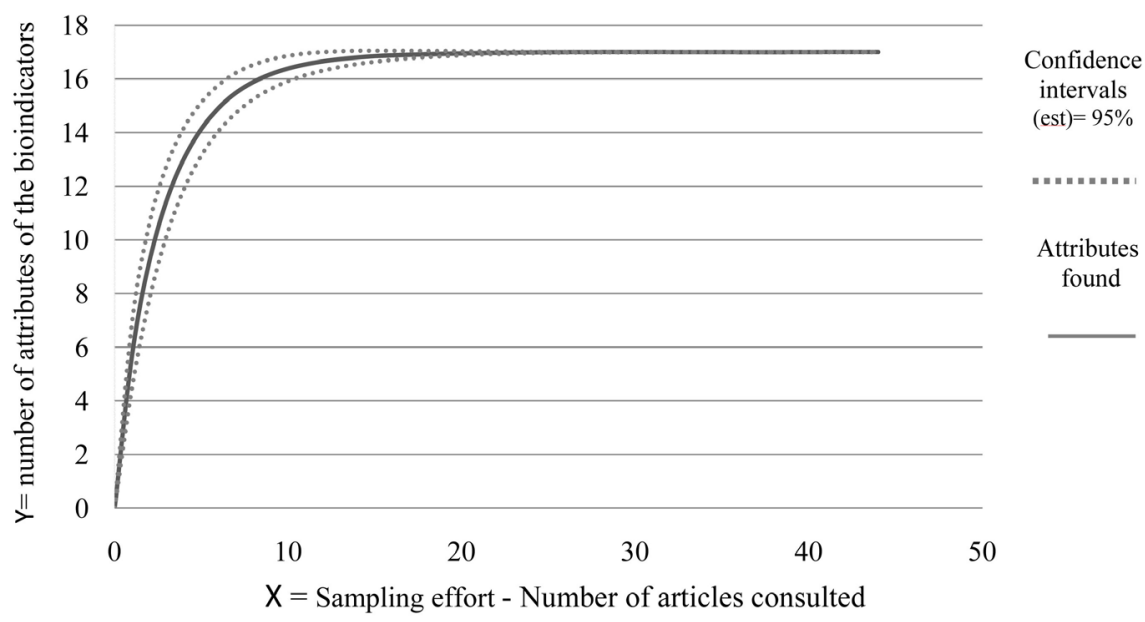

Figure 2. Attribute accumulation curve (Software Estimates 9.1.0). 
Table 1. Attributes of the biotic indicators and their representativeness in the theoretical sampling.

\begin{tabular}{lc}
\hline \multicolumn{1}{c}{ Attribute } & $\begin{array}{c}\text { Representativeness of } \\
\text { scientific use (Among } \\
\text { the sources consulted) }\end{array}$ \\
\hline 1) Sensitive & $68 \%$ \\
2) Calculation or simple and economic analysis & $68 \%$ \\
3) Reflects effects on a large scale & $52.2 \%$ \\
4) Sufficient ecological and biological information about & $36.3 \%$ \\
the bioindicator (Natural History) & $34 \%$ \\
5) Biologically relevant & $34 \%$ \\
6) Sufficient permanent abundance & $32 \%$ \\
7) Known taxonomic identity & $32 \%$ \\
8) Is presented permanently, allowing monitoring over time & $29.5 \%$ \\
9) Rate of response to changes in the environment (Anticipatory) & $29.5 \%$ \\
10) Reflects particular tensions, differentiating natural tendencies & \\
and anthropogenic stress & $27.2 \%$ \\
11) Presents low variability & $25 \%$ \\
12) Quantifiable or Measurable & $25 \%$ \\
13) Socially relevant & $25 \%$ \\
14) Reflect utility functions & $22.7 \%$ \\
15) Provides differentiating information & \\
16) Narrow Range of adaptation, Singular species & \\
17) Biologically integrative & \\
\hline
\end{tabular}

Type of attributes: Biotic $\square$, Technical $\square$, Social or Economic $\square$.

1) Sensitivity: Ideally, the bioindicator species must respond to the tensions of the system that result from human actions or natural factors. Perhaps, the most useful bioindicator is the one that shows high sensitivity to a type of subtle, particular and differentiable stress [3] [4] [6] [7] [11] [12] [15] [18] [19] [21] [23]-[42].

2) Calculation or simple and economic analysis: Refers to the way in which is possible to study or sample a species or group of them. In case of not arriving at an asymptote in a prudent time, it is possible that the study is dealing with an inadequate species. Similarly, it may not be an accurate bioindicator when the process of obtaining the samples becomes expensive or involves a lot of training time to identify it. [4] [6] [7] [10] [12] [15] [18] [19] [21] [24] [25] [27] [29] [30] [32] [33] [35] [36] [37] [39] [42]-[50].

3) Reflects effects on a large scale: Applies when the information or response given by the species to some impact may reflect reactions in other species, taxonomic groups and even geographic ranges, so the information or response detected by the species can be contrasted to other levels or biotic scales 
[3] [4] [10] [12] [18] [19] [21] [23] [27] [31] [32] [33] [36] [40] [41] [42] [43] [44] [47] [49] [51] [52].

4) Sufficient ecological and biological information about the indicator: This attribute refers to the familiarity or availability of information that can be obtained about an indicator species. Also, it refers to the breadth of studies of a taxon and the proposed background in review articles, journals in biological sciences and scientific notes that contribute to the knowledge of the species of interest [10] [12] [18] [19] [21] [25] [29] [30] [33] [38] [39] [42] [43] [44] [45] [53].

5) Biologically relevant: Are those species that are fundamental or of great importance at the ecological level. Also, species that present potential impacts on a community or ecosystem and that are relevant and have effects on its abundance. Likewise, the species can be related to the maintenance of essential natural processes [15] [16] [19] [25] [34]-[40] [45] [51] [52] [54].

6) Sufficient permanent abundance: The species or group of species that are taken as an object of analysis, must be sufficiently common and abundant in the sampling area to be studied during the period of time that the research is carried out, allowing the recognition of trends or generalities about the patterns that aim to be studied without affecting the population of interest [7] [10] [12] [18] [19] [30] [34] [40] [42] [44] [45] [48] [50] [52].

7) Known taxonomic identity: Refers to the clarity regarding the taxonomy of the bioindicator species. The taxonomic checklists are useful for the recognition of the species and to have an initial knowledge of the identity of the species. Ideally, there should be no ambiguities in terms of identification of the species that imply consulting with an expert. [10] [12] [19] [21] [26] [29] [33] [40] [42] [43] [44] [45] [47] [53].

8) Is presented permanently, allowing monitoring over time: The species or indicator group must be actively present in the study area or be accessible in the lapses that include monitoring or sampling and, preferably, after the investigation in case of requiring other information in the future [3] [4] [12] [15] [16] [30] [31] [32] [35] [44] [45] [46] [50] [52].

\section{9) Rate of response to changes in the environment (Anticipatory):}

Although the indicator evidences gradual changes, ideally an observable response threshold can be expected before a situation of change or stress occurs. The change in the indicator must be measurable before a substantial change threatens the integrity of the system [10] [15] [24] [26] [29] [32] [35] [36] [44] [45] [47] [52] [54].

10) Reflects particular tensions, differentiating natural tendencies and changes in anthropogenic stress: The bioindicator must be able to provide information that makes it possible to differentiate if it responds to a natural stress or if it is an anthropic alteration. Species that can adequately respond to this criterion are potentially used to evaluate situations at the local level [4] [10] [12] [15] [16] [23] [29] [32] [36] [39] [44] [45] [52].

11) Presents low variability: It is considered important that the bioindicator 
species have low response ranges or provide monotonous responses to the stresses to which they are sensitive, due to this contributes to the accuracy and evaluation of the response to be evaluated [3] [18] [19] [23] [26] [29] [30] [32] [33] [37] [44] [47].

12) Quantifiable or Measurable: Capable of operating in a defined manner, allowing a standard procedure whose result is the contribution of information that can be interpreted and differentiated according to the logic of what is being analyzed [12] [15] [26] [27] [29] [31] [36] [37] [44] [45] [54].

13) Socially relevant: The species or groups of species may be part of concerns of general interest, may have cultural or scientific significance, and may potentially draw attention to possible decision makers [6] [11] [15] [19] [31] [36] [37] [48] [50] [51] [54].

14) Reflect utility functions: Species that can attract the attention of decision-makers because of the ecosystem services it provides. For example, species that are important for agriculture, that are candidates to counteract pests or that may have commercial importance [19] [21] [33] [36] [37] [40] [43] [44] [47] [50] [51].

15) Provides differentiating information: This type of species generates unique information through known thresholds, so it is not redundant or ambiguous compared to the information provided by other species [4] [15] [23] [24] [25] [29] [37] [40] [44] [51].

16) Narrow Range of adaptation, Singular species (stenoic): This type of species has low distributions or reduced range of mobility. They are also considered as sessile species of easy approach and may be useful to complement investigations at the local or conservation level. [7] [10] [16] [19] [28] [29] [42] [43] [48].

17) Biologically integrative: Bioindicators of this type offer a range that provides a measure or reference of the coverage according to key gradients in the biological systems. In case the population analysis fulfills this attribute, the answers or tendencies obtained can be contrasted with other taxa or gradients of the biot [15] [24] [34] [35] [37] [40].

The frequency of each attribute along the theoretical sampling presents variation if the range of the time is taken into account. As a result of the sampling, it is observed that attributes such as "sensible" and "simple and economic calculation" have a maximum representativeness among the sources consulted, equivalent to $68 \%$; while the attribute "integrative biologically" has the lowest representativeness, equivalent to 13 . $6 \%$. A repetition pattern associated with the sampling trend is not observed. However, for the case of the attributes "Quantifiable or Measurable", "Socially relevant" and "Reflect utility functions" the trend along the sampling is the same, since they show a representativeness of $25 \%$ when described by 12 authors. It is recognized that those attributes that exhibit a greater representativeness tend to cover higher temporal ranges in terms of its use in scientific sources, while those with low representativeness tend to have low temporal ranges of scientific use. 
There is a discussion between the use of indicators to evaluate the past or present conditions of a natural environment and the prediction of the future through modeling [3]. Factors such as climate, diseases and anthropogenic aspects increase the level of complexity and diminish certainties or predictions. However, it is prudent to use bioindicators to study habitat conditions and its quality. In many cases, socioeconomic and ecological criteria are used to select the species that will be taken to conduct a modeling study. As mentioned, it is feasible to include groups of species that are of high public interest or have some economic importance [12].

Ten differentiated attributes have emerged throughout the sampling. Its temporal range covers from 1990 to 2014. It is recognized that, although these attributes do not have high representativeness and are proposed by a small number of authors, they can be references that complement the traditional selection criteria associated with bioindicator species. Among these emerging attributes, there can be reported the intrinsic stochasticity [25]; how species can be related to the environment, ecological integrity and human health [36]; how species can be used or identify by people who do not necessarily are specialists [20] [31] [36]; and how they can represent an interesting topic for sustainable development [31], (See Figure 3).

\section{Discussion}

When developing studies on bioindicator species it is important to be clear about what is being evaluated or monitored and why [6]. Biodiversity and its dynamics in natural environments must be understood beyond particular indices referring to anthropocentric aspects of health. The bioindicators can be selected based on the levels of organization of the ecosystem. It is necessary to recognize that although there are positive bioindicators that measure ecotoxicological effects, there are also species that thrive under conditions of alteration or
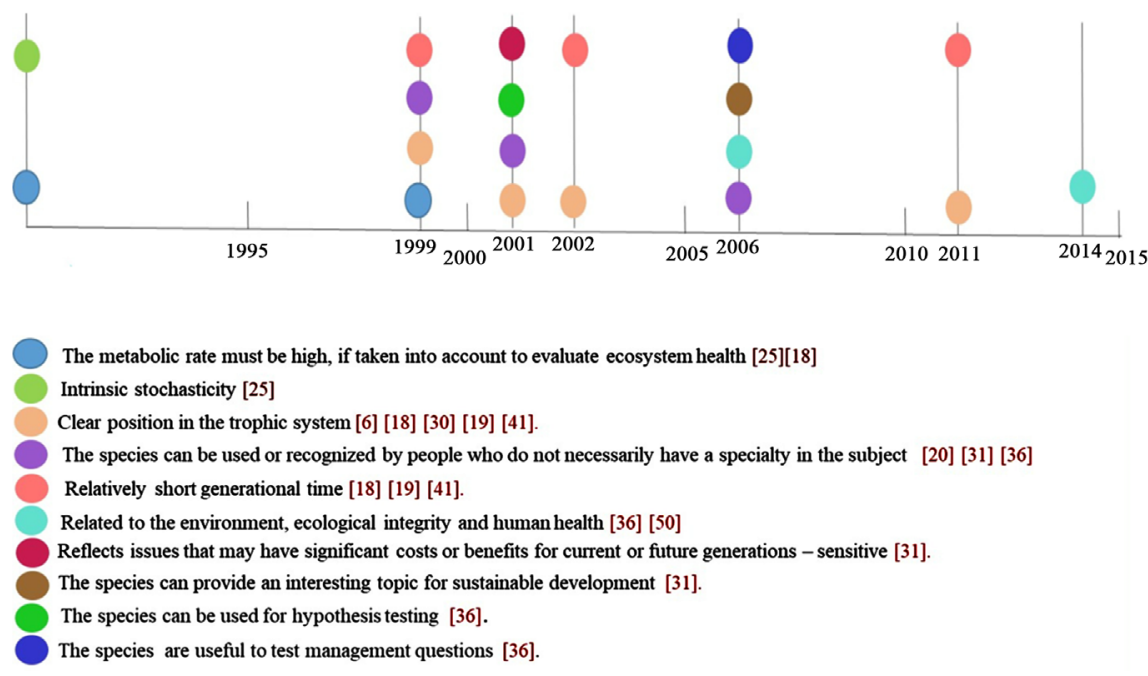

Figure 3. Alternate attributes around the revision. 
that follow the human activities that they are disturbing [12]. The natural ecosystems include systems dominated by man and have been called "complex adaptive ecosystems". These systems, more than mechanistic and predictable, are characterized for exhibiting a limited degree of predictability, and reflect restrictions that the evolutionist dynamic offers to ecosystems, which is a key aspect for its sustainability [13].

Around the mentioned principles, and in contrast to the traditional use of bioindicators, there is the possibility of reversing that situation in which a species or a group of them reflect physiologically impacts derived from anthropocentric activities and, instead of these, the species can reflect aspects that contribute to the valuation of the ecosystem and supports the answers of the questions related to: How can anthropic activities affecting ecosystems be evidenced of principles associated with bioindication? How do human beings attribute value to natural environments, taking as reference biotic indicators? or How is a bioindicator and its attributes capable of reflecting human attitudes or behaviors around ecosystems?

If considered the time lapse in which the theoretical sampling has been carried out and making reference to recent studies, it is common to find that different investigations that describe theoretical fundaments on the biotic indicators are not concerned with questioning the context of the bioindication and its history. Therefore, the studies are casuistic and oriented to solve problems of predictive and ecotoxicological order [7]. With this, it is not meant that each study should have an analysis on these fundaments, but it should at least justify the criteria that have been taken into account both for the selection of bioindicators and the sense of carrying out the study under those principles. This with the aim to avoid ambiguities and highlight alternative benefits to purely ecological studies and generate alternatives related to the study of the environment, integrity and human welfare.

With the intention of generating alternate routes to the traditional ones on the use of bioindicator species in terms of economic valuation, it is considered that the studies, and in general the protection of sustainable ecosystems, should form interdisciplinary teams that include not only ecologists or naturalists but other fields of knowledge, such as earth sciences, physical sciences, social sciences, arts and humanities, which generates a dialogue from different perspectives.

\section{Conclusions}

This review is product of an effort to track which are the desirable attributes in a biotic indicator and, although these characteristics have been intermittent in terms of their recognition over time in different academic sources, a consensus of scientifically accepted qualities or attributes has been proposed. Nevertheless, and as a result of theoretical sampling, there has been evidenced the emergence of some attributes that contribute to the traditional principles of bioindication and the proposed consensus. In terms of economic valuation and under the logic of this review, it is prudent to make visible a common language referring to the 
minimums of the bioindication as well as qualities or attributes that, despite not showing a broad representativeness, can describe more fully the characteristics that are important for an indicator species and how it can reflect the profits that human beings get from the natural environments.

It is relevant to be aware that, although an indicator species will not fully comply with the desired attributes and each investigation responds to particular interests according to the criterion of the researcher or the decision maker, it is necessary to consider some basic qualities of the species as a model of study. This is because the categories that are part of the described attributes do not only obey the biological or ecological order, but also cover other technical, social or economic contexts in response to the multiple factors that make up the complexity of natural systems. In the same way, it is recognized that each attribute represents a sample of the whole that makes up the essence of a bioindicator. This means that each attribute, seen in a particular way, shows a reference in which it is possible to understand the integral generality of the identity of the bioindicator, a fact on which the hologrammatic principle is governed.

\section{Conflicts of Interest}

The authors declare no conflicts of interest regarding the publication of this paper.

\section{References}

[1] De Alba, E. and Reyes, A (1998) Valoración económica de los recursos del paísMéxico. In: La diversidad biológica de México: Estudio de País-Comisión Nacional Para el Conocimiento y uso de la Biodiversidad, Conabio, México D.F., 211-237.

[2] Gomez-Baggethun, E. and de Groot, R. (2007) Capital natural y funciones de los ecosistemas: Explorando las bases ecológicas de la economía. Ecosistemas, 16, 4-14.

[3] Landers, P.B., Verner, J. and Thomas, J.W. (1988) Ecological Uses of Vertebrate Indicator Species: A Critique. Society for Conservation Biology, 2, 316-328. https://doi.org/10.1111/j.1523-1739.1988.tb00195.x

[4] Riiters, K.H., Law, B.E., Kucera, R.C., Gallant, A.L., Dc Velice, R.L. and Palmer, C.J. (1990) A Selection of Forest Condition Indicators for Monitoring. Environmental Monitoring and Assessment, 20, 21-33. https://doi.org/10.1007/BF00396518

[5] González, V., Ochoa, S., Pozo, C., Gordon, B., Ferguson, L., Rangel-Ruiz, J., Arriaga-Weiss, S., Ponce-Mendoza, A. and Kampichler, C. (2011) Indicadores ecológicos de hábitat y biodiversidad en un paisaje neotropical: Perspectiva multitaxonómica. Revista de Biologia Tropical, 59, 1433-1451.

[6] Noss, R.F. (1990) Indicators for Monitoring Biodiversity: A Hierarchical Approach. Conservation Biology, 12, 822-835. https://doi.org/10.1111/j.1523-1739.1990.tb00309.x

[7] Büch, W. (2003) Biotic Indicators for Biodiversity and Sustainable Agriculture. Elsevier Science, Amsterdam.

[8] Polanía, J. (2010) Indicadores biológicos para el monitoreo de puertos en Colombia. Revista Gestión y Ambiente, 13, 75-86.

[9] Kay, J.J. and Regier, H. (2000) Uncertainty, Complexity, and Ecological Integrity: 
Insights from an Ecosystem Approach. In: Crabbé, P., Holland, A., Ryszkowski, L. and Westra, L., Eds., Implementing Ecological Integrity: Restoring Regional and Global Environmental and Human Health, Springer Science + Business Media, Dordrecht, 121-156. https://doi.org/10.1007/978-94-011-5876-3_9

[10] Pinilla, G. (1998) Indicadores biológicos en ecosistemas acuáticos de Colombia. Compilación bibliográfica Fundación Universitaria Jorge Tadeolozano, Bogotá-Colombia, $65 \mathrm{p}$.

[11] Rempel, R., Naylor, B., Elkie, P., Baker, J., Churcher, J. and Gluck, J. (2015) An Indicator System to Assess Ecological Integrity of Managed Forests. Ecological Indicators, 60, 860-869. http://www.elsevier.com/locate/ecolind https://doi.org/10.1016/j.ecolind.2015.08.033

[12] Feinsinger, P. (2004) Diseño Estudios de Campo Para La Conservación. Traducido por: Gustavo Kattan y Carolina Murcia. Wildlife Conservation Society-Editorial FAN Bolivia y the Nature Conservancy.

[13] Costanza, R., Cumberland, J., Daly, H., Goodland, R. and Nogaard, R. (1999) Una introducción a la Economía Ecológica. Traducción José Manuel Salazar Palacios; Revisión técnica Diana Piloyan Continental, México.

[14] Brander, L., Gómez-Baggethun, E., Martín-López, B. and Verma, M. (2010) The Economics of Valuing Ecosystem Services and Biodiversity-The Economics of Ecosystems and Biodiversity: The Ecological and Economic Foundations (TEEB Document).

[15] Cairns, J.Jr., McCormick, P.V. and Niederlehner, B.R. (1993) A Proposed Framework for Developing Indicators of Ecosystem Health. Hydrobiologia, 263, 1-44. https://doi.org/10.1007/BF00006084

[16] Noss, R.F. (1999) Assessing and Monitoring Forest Biodiversity: A Suggested Framework and Indicators. Forest Ecology and Management, 115, 135-146. https://doi.org/10.1016/S0378-1127(98)00394-6

[17] González Zuarth, C.A., Vallarino, A., Pérez, J. and Low, A. (2014) Bioindicadores Guardianes de nuestro futuro ambiental Primera edición: 2014 Instituto Nacional de Ecología y Cambio Climático (INECC) San Cristóbal de Las Casas, Chiapas.

[18] Caro, A.T.M. and Doherty, G.O. (1999) On the Use of Surrogate Species in Conservation Biology. Conservation Biology, 13, 805-814. https://doi.org/10.1046/j.1523-1739.1999.98338.x

[19] Gerhardt, A. (2002) Bioindicator Species and Their Use in Biomonitoring. Environmental Monitoring-Vol. I-Bioindicator Species and Their Use in Biomonitoring, Encyclopedia of Life Support Systems (EOLSS).

[20] Ferris, R. and Humphrey, J.W. (1999) A Review of Potential Biodiversity Indicators for Application in British Forests. Forestry, 72, 313-328. https://doi.org/10.1093/forestry/72.4.313

[21] Gayubo, S.F., González, J.A., Asís, J.D. and Tormos, J. (2005) Conservation of European Environments: The Spheciformes Wasps as Biodiversity Indicators (Hymenoptera: Apoidea, Ampulicidae, Sphecidae and Crabronidae). Journal of Natural History, 39, 2705-2714. https://doi.org/10.1080/00222930500114095

[22] Metzger, J.P. (2006) How Deal with Non-Obvious Rules for Biodiversity Conservation in Fragmented Areas. Natureza \& Conservacao, 4, 125-137.

[23] Herricks, E.E. and Schaeffer, D.J. (1985) Can We Optimize Biomonitoring? Environmental Management, 9, 487-492. https://doi.org/10.1007/BF01867323

[24] Liverman, D.M., Hanson, M.E., Brown, B.J. and Merideth, R.W. (1988) Global Sus- 
tainability: Toward Measurement. Environmental Management, 12, 133-143. https://doi.org/10.1007/BF01873382

[25] Kelly, J.R. and Harwell, M.A. (1990) Indicators of Ecosystem Recovery. Environmental Management, 14, 527-545. https://doi.org/10.1007/BF02394708

[26] Kremen, C. (1992) Assessing the Indicator Properties of Species Assemblages for Natural Areas Monitoring. Ecological Applications, 2, 203-217. https://doi.org/10.2307/1941776

[27] Keddy, P.A., Lee, H.T. and Wisheu, I.C. (1993) Choosing Indicators of Ecological Integrity: Wetlands as a Model System. In: Woodley, S., Kay, J. and Francis, G., Eds., Ecological Integrity and the Management of Ecosystems, St-Lucie Press, St. Lucie, 61-82.

[28] Paoletti, M.G. (1999) Using Bioindicators Based on Biodiversity to Assess Landscape Sustainability. Agriculture, Ecosystems and Environment, Vol. 74, 1-18. https://doi.org/10.1016/B978-0-444-50019-9.50004-2

[29] Hilty, J. and Merenlender, A. (2000) Faunal Indicator Taxa Selection for Monitoring Ecosystem Health. Biological Conservation, 92, 185-197. https://doi.org/10.1016/S0006-3207(99)00052-X

[30] Burger, J. and Gochfeld, M. (2001) On Developing Bioindicators for Human and Ecological Health. Environmental Monitoring and Assessment, 66, 23-46. https://doi.org/10.1023/A:1026476030728

[31] Camacho-Sandoval, J. and Duque, H. (2001) Indicators for Biodiversity Assessment in Costa Rica. Agriculture, Ecosystems and Environment, 87, 141-150. https://doi.org/10.1016/S0167-8809(01)00274-2

[32] Dale, V.H. and Beyeler, S.C. (2001) Challenges in the Development and Use of Ecological Indicators. Ecological Indicators, 1, 3-10. https://doi.org/10.1016/S1470-160X(01)00003-6

[33] Olsgard, F., Brattegard, T. and Holthe, T. (2003) Polychaetes as Surrogates for Marine Biodiversity: Lower Taxonomic Resolution and Indicator Groups. Biodiversity and Conservation, 12, 1033-1049. https://doi.org/10.1023/A:1022800405253

[34] de Heer, M., Kapos, V. and ten Brink, B.J.E. (2005) Biodiversity Trends in Europe: Development and Testing of a Species Trend Indicator for Evaluating Progress towards the 2010 Target. Philosophical Transactions of the Royal Society B: Biological Sciences, 360, 297-308. https://doi.org/10.1098/rstb.2004.1587

[35] Leonard, D.R.P., Clarke, K.R., Somerfield, P.J. and Warwick, R.M. (2006) The Application of an Indicator Based on Taxonomic Distinctness for UK Marine Biodiversity Assessments. Journal of Environmental Management, 78, 52-62. https://doi.org/10.1016/j.jenvman.2005.04.008

[36] Burger, J. (2006) Bioindicators: Types, Development, and Use in Ecological Assessment and Research. Environmental Bioindicators, 1, 22-39. https://doi.org/10.1080/15555270590966483

[37] Bartell, S.M. (2006) Biomarkers, Bioindicators, and Ecological Risk Assessment-A Brief Review and Evaluation. Environmental Bioindicators, 1, 60-73. https://doi.org/10.1080/15555270591004920

[38] Moreno, C.E., Rojas, G.S., Pineda, E. and Escobar, F. (2007) Shortcuts for Biodiversity Evaluation: A Review of Terminology and Recommendations for the Use of Target Groups, Bioindicators and Surrogates. International Journal of Environment and Health, 1, 71. https://doi.org/10.1504/IJENVH.2007.012225

[39] Isasi-Catalá, E. (2011) Los conceptos de especies indicadoras, paraguas, banderas y 
claves: Su uso y abuso en ecología de la conservación. Interciencia, 36, 31-38. http://www.interciencia.org/v36_01/031.pdf

[40] Heink, U. and Kowarik, I. (2010) What Criteria Should Be Used to Select Biodiversity Indicators? Biodiversity and Conservation, 19, 3769-3797.

https://doi.org/10.1007/s10531-010-9926-6

[41] Herrera, F.F. and Cuevas, E. (2011) Artrópodos del suelo como bioindicadores de recuperación de sistemas perturbados, Centro de Ecología, Instituto Venezolano de Investigaciones Científicas. Venesuelos, 11, 67-78.

[42] Vergara, P.A. (2015) Caracterización de la degradación y los cambios de usos de suelo en fincas ganaderas y su relación con la diversidad de aves en el Valle del Río Cesar, Colombia-Centro Agronómico Tropical de Investigación y EnseñanzaCATIE.

[43] Pearson, D.L. (1994) Selecting Indicator Taxa for the Quantitative Assessment of Biodiversity. Philosophical Transactions of the Royal Society B: Biological Sciences, 345, 75-79. https://doi.org/10.1098/rstb.1994.0088

[44] McGeoch, M.A. (1998) The Selection, Testing and Application of Terrestrial Insects as Bioindicators. Biological Reviews of the Cambridge Philosophical Society, 73, 181-201. https://doi.org/10.1017/S000632319700515X

[45] Carignan, V. and Villard, M. (2002) Selecting Indicator Species to Monitor Ecological Integrity: A Review. Environmental Monitoring and Assessment, 78, 45-61. https://doi.org/10.1023/A:1016136723584

[46] Conti, M.E. and Cecchetii, G. (2001) Biological Monitoring; Lichens as Bioindicators of Air Pollution Assessment a Review. Environmental Pollution, 114, 471-492. https://doi.org/10.1016/S0269-7491(00)00224-4

[47] Rainio, J. and Niemela, J. (2003) Ground Beetles (Coleoptera: Carabidae) as Bioindicators. Biodiversity and Conservation, 12, 487-506. https://doi.org/10.1023/A:1022412617568

[48] Niemi, G.J. and McDonald, M.E. (2004) Application of Ecological Indicators. Annual Review of Ecology, Evolution, and Systematics, 35, 89-111. https://doi.org/10.1146/annurev.ecolsys.35.112202.130132

[49] Hagan, J.M. and Whitman, A.A. (2006) Biodiversity Indicators for Sustainable Forestry: Simplifying Complexity. Journal of Forestry, 104, 203-210. https://academic.oup.com/jof/article/104/4/203/4598705

[50] Cabrera-Dávila, G. (2014) Manual práctico sobre la macrofauna edáfica como indicador biológico de la calidad del suelo, producto del proyecto "Impacto de la intensidad de uso de la tierra sobre la macrofauna del suelo en el Occidente de Cuba. La macrofauna como bioindicador de la fertilidad del suelo".

[51] Mackey, B.G., McKenney, D.W. and Sims, R.A. (1994) Towards a Set of Biodiversity Indicators for Canadian Forests. In: McKenney, D.W., Sims, R.A., Soulé, M.E., Mackey, B.G. and Campbell, K.L., Eds., Towards a Set of Biodiversity Indicators for Canadian Forests. Proceedings of a Forest Biodiversity Indicators Workshop, Natural Resources Canada, Sault Ste-Marie, 23-51.

[52] Lindenmayer, D.B., Margules, C.R. and Botkin, D.B. (2001) Indicators of Biodiversity for Ecologically Sustainable Forest Management. Conservation Biology, 14, 941-950. https://doi.org/10.1046/j.1523-1739.2000.98533.x

[53] Parra, A., Ortero, J.T., Sandino, J.C. and Ospina, R. (2016) Abejas de las orquídeas (Hymenoptera: Apidae: Euglossini) y su importancia como polinizadoras de amplio 
rango en ecosistemas naturales-Iniciativa Colombiana de Polinizadores-Abejas.

[54] Suter, G.W. (1990) Endpoints for Regional Ecological Risk Assessments. Environmental Management, 14, 9-23. https://doi.org/10.1007/BF02394015 